Yüzüncü Yil Üniversitesi
Tarim Bilimleri Dergisi

Araştırma Makalesi (Research Article)

\title{
Bazı Biber (Capsicum annuum L.) Genotiplerinin Anter Kültürü Performanslarının Belirlenmesi
}

\author{
Didem ATASOY ${ }^{1}$, Gökhan BAKTEMUR ${ }^{2}$, Hatıra TAŞKIN ${ }^{3 *}$ \\ ${ }^{1,2,3}$ Çukurova Üniversitesi, Ziraat Fakültesi, Bahçe Bitkileri Bölümü, 01330, Adana, Türkiye \\ ${ }^{1} \mathrm{https}$ //orcid.org/0000-0003-0659-2943 ${ }^{2} \mathrm{https} / / /$ orcid.org/0000-0002-0362-5108 ${ }^{3} \mathrm{https}: / /$ orcid.org/0000-0002-1784-4731 \\ *Sorumlu yazar e-posta: hatirataskin1@gmail.com
}

\section{Makale Bilgileri}

Geliş: 04.12.2020

Kabul: 23.05.2021

Online Yayınlanma 30.06.2021

DOI: $10.29133 /$ yyutbd.835106

Anahtar kelimeler

Anter kültürü,

Biber,

Capsicum annuum,

Genotip.
Öz: Bu çalışmada, farklı tiplerde 23 biber genotipinde anter kültürü performansı belirlenmiştir. Çiçek tomurcuklarının dezenfeksiyonunda, tomurcuklar öncelikle $\%$ 70'lik etil alkolde 30 saniye bekletilmiş ve sonrasında 10 dakika \% 15'lik sodyum hipoklorit çözeltisinde tutulmuşlardır. Anterler ilk aşamada; $30 \mathrm{~g} / \mathrm{L}$ sakkaroz, $2.5 \mathrm{~g} / \mathrm{L}$ aktif kömür, $15 \mathrm{mg} / \mathrm{L}$ gümüş nitrat $\left(\mathrm{AgNO}_{3}\right), 4 \mathrm{mg} / \mathrm{L} \mathrm{1-}$ Naphthaleneacetic acid (NAA), $0.5 \mathrm{mg} / \mathrm{L}$ 6-Benzylaminopurine (BAP) ve 6.5 $\mathrm{g} / \mathrm{L}$ agar içeren Murashige and Skoog (MS) besin ortamında kültüre alınmışlardır. Sonrasında anterler, $30 \mathrm{~g} / \mathrm{L}$ sakkaroz ve $6.5 \mathrm{~g} / \mathrm{L}$ agar içeren ve büyümeyi düzenleyici içermeyen $\mathrm{MS}$ besin ortamına aktarılmışlardır. Elde edilen embriyolarda, aynı besin ortamına alınmışlardır (ikinci ortama). Anterler, ön uygulama olarak, $+35^{\circ} \mathrm{C}$ 'de ve karanlık koşullarda 2 gün süresince bekletilmişlerdir. Çalışma sonuçları değerlendirildiğinde, genotiplere göre 100 anter için ortalama embriyo sayıları 0.83 ile 44.44 arasında değişmiş̧tir. En yüksek oran, FT-509 genotipinde gözlemlenmiş ve bu genotipi FT-508 (23.61 embriyo/100 anter), FT-1181 (23.37 embriyo/100 anter) ve FT-905 (22.89 embriyo/100 anter) genotipleri takip etmiştir. En düşük performansı, 0.83 adet embriyo/100 anter ile FT-1178 genotipi göstermiştir. Oluşan embriyoların tamamı, bitkiye dönüşebilmiştir. Bu nedenle, 100 anter için ortalama bitki oluşturan embriyo sayısı değerleri, 100 anter için ortalama embriyo sayıları ile aynı olmuştur. En yüksek ortalama bitki sayısı 20 adet ile FT-508 no'lu genotipte gözlemlenmiş ve FT-509 (17.5 bitki), FT-1181 (16 bitki), FT-905 (12 bitki), FT-263 (10.5 bitki) ile FT-507 (8.25 bitki) genotipleri tarafindan takip edilmiştir. En düşük bitki sayısı ise 0.5 adet ile FT-1178 no'lu genotipte kaydedilmiştir.

\section{Determination of Anther Culture Performance of Some Pepper (Capsicum annuum L.) Genotypes}

\section{Article Info}

Received: 04.12 .2020

Accepted: 23.05.2021

Online Published 30.06.2021

DOI: $10.29133 /$ yyutbd.835106

Keywords

Anther culture,

Pepper,
Abstract: In this study, anther culture performances of 23 pepper genotypes belonging different types were determined. In disinfection of flower buds, the buds were first kept in 70\% ethyl alcohol for 30 seconds and then were waited in $15 \%$ sodium hypochlorite solution for 10 minutes. The anthers were cultured in Murashige and Skoog (MS) nutrient medium containing $30 \mathrm{~g} \mathrm{~L}^{-1}$ sucrose, 2.5 $\mathrm{g} \mathrm{L}^{-1}$ activated charcoal, $15 \mathrm{mg} \mathrm{L}^{-1}$ silver nitrate $\left(\mathrm{AgNO}_{3}\right), 4 \mathrm{mg} \mathrm{L} \mathrm{L}^{-1}$ 1Naphthaleneacetic acid (NAA), $0.5 \mathrm{mg} \mathrm{L}^{-1}$ 6-Benzylaminopurine (BAP) and 6.5 $\mathrm{g} \mathrm{L}^{-1}$ agar in the first stage. The anthers were then transferred to MS medium including $30 \mathrm{~g} \mathrm{~L}^{-1}$ sucrose and $6.5 \mathrm{~g} \mathrm{~L}^{-1}$ agar and without growth regulators. The embryos obtained were taken to the same nutrient medium (second one). The 
Capsicum annuum, Genotype. anthers were cultured at $+35^{\circ} \mathrm{C}$ and in dark conditions for 2 days as pretreatment. When the results of the study were evaluated, average embryo number per hundred anthers according to the genotypes ranged from 0.83 to 44.44. The highest ratio was observed in the genotype FT-509 and it was followed by the genotypes FT-508 (23.61 embryos/100 anthers), FT-1181 (23.37 embryos/100 anthers) and FT-905 (22.89 embryos/100 anthers). The genotype FT-1178 showed the lowest performance with 0.83 embryos/100 anthers. All of the embryos developed could transform into plants. Therefore, the average embryo number forming plant per 100 anthers was the same with average embryo number per hundred anthers. The highest average plant number was observed in the genotype FT-508 with 20 plants and it was followed by the genotypes FT-509 (17.5 plants), FT-1181 (16 plants), FT-905 (12 plants), FT263 (10.5 plants) and FT-507 (8.25 plants). The lowest number of plant was recorded in the genotype FT-1178 with 0.5 plant.

\section{Giriş}

Anavatanı Amerika kıtası olan biber (Öntürk ve Çürük, 2019; Eroğlu ve ark., 2020), Solanaceae familyası ve Capsicum cinsi içerisinde yer alır. Birçok türü barındıran Capsicum cinsinde, en çok tüketimi yapılan tür Capsicum annuum L.'dur. Türkiye'nin 2018 yılında kapya biber üretimi 1 128060 ton, dolmalık üretimi 397175 ton, sivri üretimi 930349 ton, çarliston üretimi ise 99390 ton (toplam 2554974 ton) iken, 1988 verileri incelendiğinde kapya ve çarliston için kayıtlı üretim bulunamazken, dolmalık üretim 470000 ton, sivri üretim ise 260000 ton olmuştur (TÜIKK, 2018). Örtüaltı dolmalık biber üretimi 1996'da 21870 ton iken, 2018'de 100253 ton, 1996 yılına kapya tipinde biber üretimi gerçekleştirilmezken 2018'de 136242 ton, sivri üretimi 1996'da 261205 ton iken, 2018'de 282029 ton, çarliston üretimi 1996'da gerçekleştirilmezken, 2018'de 70645 ton olarak kaydedilmiştir (TÜIK, 2018). Dünya taze ve kuru toplam biber üretiminde 2018 y1lı FAO verilerine göre; ilk sırayı 18506001 ton ile Çin alırken, Çin'i sırası ile 3440044 ton ile Meksika, 2569269 ton ile Türkiye, 2542358 ton ile Endonezya, 1887679 ton ile Hindistan, 1281896 ton ile İspanya, 818 238 ton ile Nijerya, 776321 ton ile Misır ve 706225 ton ile Amerika Birleşik Devletleri izlemektedir. Sadece taze biber üretiminde 18184711 ton ile yine Çin ilk sırada, 3379289 ton ile Meksika ikinci, 2 554974 ton ile Türkiye üçüncü, 2542358 ton ile Endonezya dördüncü, 1275457 ton ile İspanya beşinci, 747367 ton ile Nijerya altıncı, 713752 ton ile Misır yedinci ve 705790 ile Amerika Birleşik Devletleri sekizinci sırada yer almaktadır. Sadece kuru biber üretiminde ise ilk sirada 1808011 ton ile Hindistan yer almaktadır. Hindistan'1 321290 ton ile Çin, 294299 ton ile Etiyopya, 247010 ton ile Tayland, 148114 ton ile Pakistan, 141177 ton ile Bangladeş ve 130335 ton ile Myanmar izlemektedir (FAO, 2018). Türkiye toplam taze ve kuru ve aynı zamanda sadece taze biber üretiminde dünya üçüncülügünü korumakla beraber, Endonezya'nın çok az bir farkla Türkiye'yi takip etmesi de dikkate değer bir durumdur. Kuru biber üretiminde ise Hindistan'ın çok açık şekilde görülebilecek üstünlüğü bulunmaktadır.

Sebze 1slahında doku kültürü yöntemlerinden, haploid bitki üretimini hedefleyen erkek gametten haploid uyartımı (androgenesis) ve dişi gametten haploid uyartımı (ginogenesis) ve partenogenesis önemli kolaylıklar ve zamandan kazanım sağlamaktadırlar. Erkek gametten haploid uyartımı anter kültürü ve mikrospor kültürü; dişi gametten haploid uyartımı ise ovül ve ovaryum kültüründen oluşmaktadır. Kromozom eliminasyonu ve eksik veya yetersiz polenle tozlama yöntemleri de haploid bitki üretimi amaçlı kullanılmaktadır. Günümüze kadar yapılan çalışmalarda, biberde bu yöntemlerden anter kültürünün başarılı bir şekilde uygulanabildiği görülmüş ve uygun bir protokolün oluşturulması amacı ile çalışmalar devam ettirilmektedir. Biber anter kültürü için, çok sayıda besin ortamı bileşimi çalışılmış ve başarılı protokoller geliştirilmiştir (Buyukalaca ve ark., 2004; Taşkin ve ark., 2011; Ata ve ark., 2019, Shimira ve ark., 2019a). Haploid embriyo oluşumunda başarıyı en fazla etkileyen faktörler; donör bitki, genotip, kültür ortamı içeriği, büyüme düzenleyicileri ve konsantrasyonları olarak bilinmektedir.

Çömlekçioğlu ve Ellialtıoğlu (2018) tarafından yapılan bir derleme çalışmasında, ülkemizde biberde anter kültürü konusunda yapılan çalışmalar ayrıntılı bir şekilde sunulmuştur. Türkiye'de, 1983 yılında ve takip eden 37 yıl boyunca biberlerden (Capsicum sp.) haploidlerin elde edilmesi çabalarının 
başlangıcından bu yana, çalışmaların amacı, çoğunlukla donör genotiplerin, besin ortamı bileşimi ve katk1 maddelerinin, büyüme düzenleyicilerin, inkübasyon koşullarının, donör bitki büyüme koşullarının ve anterlerin alındığı farklı zamanların etkilerine odaklanarak yeni etkili teknikler geliştirmek olmuştur (Çömlekçioğlu ve Ellialtıoğlu, 2018). Bu yöntemle oluşturulan haploid bitkilerden elde edilen saf hatlar, yeni çeşitlerin geliştirilmesinde başarıyla kullanılmaktadır (Çömlekçioğlu \& Ellialtığlu, 2018). Sunulan bu çalışmanın amacı, 23 farklı biber genotipinde anter kültürü performansının belirlenmesidir. Çalışmada kullanılan genotipler, özel bir firma tarafından sslah çalışmalarında kullanılmaktadır. Bu genotiplerin androgenesis etkinliklerinin belirlenmesi ve bu genotiplerden dihaploid bitkilerin elde edilmesi ile özel firma tarafından yürütülen sslah çalışmaları hızlandırılmış olacaktır.

\section{Materyal ve Yöntem}

Çalışma 2018-2019 yılları arasında, ARGEERA Bilimsel Araştırma Geliştirme Üretim Danışmanlık San. ve Tic. Ltd. Şti. (Antalya)'nde yürütülmüş̧ür. Bitkisel materyal olarak, 1slah çalışmalarında kullanılan ve özel firma tarafından kodlanan (Semillas Fitó, İspanya) 23 adet biber genotipi kullanılmıştır. Genotiplerin kodları ve tipleri Çizelge 1'de sunulmuştur.

Çizelge 1. Çalışmada kullanılan biber genotipleri

\begin{tabular}{ll}
\hline Genotip No & Tip \\
\hline FT-263 & Sivri \\
FT-500 & Çarliston \\
FT-501 & Çarliston \\
FT-507 & Çarliston \\
FT-508 & Çarliston \\
FT-509 & Çarliston \\
FT-900 & Kapya \\
FT-901 & Kapya \\
FT-902 & Kapya \\
FT-903 & Kapya \\
FT-905 & Kapya \\
FT-906 & Kapya \\
FT-907 & Kapya \\
FT-908 & Kapya \\
FT-1173 & Dolma \\
FT-1174 & Dolma \\
FT-1175 & Dolma \\
FT-1178 & Dolma \\
FT-1179 & Dolma \\
FT-1180 & Dolma \\
FT-1181 & Dolma \\
FT-1182 & Dolma \\
FT-1183 & Dolma \\
\hline
\end{tabular}

Genotiplere ait tohumların ekimi, 2018 yılı Ağustos ayında, içerisinde 2 hacim torf ve 1 hacim perlit bulunan viyollere yapılmıştır. Eylül ayı içerisinde, 6-7 gerçek yapraklı dönemde iken fideler, her genotipden 30 bitki olacak şekilde, 110 × 50 × $50 \mathrm{~cm}$ aralıklarla plastik seraya dikilmişlerdir. Bitki gelişimi boyunca gerekli bakım işlemleri (sulama, gübreleme, budama, hastalık ve zararlılarla mücadele, yabancı otların temizlenmesi vb.) dikkatli bir şekilde uygulanmıştır.

Denemelere başlarken anter kültürü için uygun aşama, asetokarmen ile boyama yöntemiyle teyit edilmiştir (Keleş ve ark., 2015). Sera koşullarında yetiştirilen ve çiçeklenmeye başlayan bitkilerden, uygun anter safhasına sahip tomurcuklar, sabahın erken saatlerinde toplanarak, doku kültürü laboratuvarına getirilmiş ve yüzey sterilizasyonuna tabi tutulmuşlardır. $\mathrm{Bu}$ amaçla tomurcuklar, steril kabin içerisinde \% 70'lik etil alkolde 30 saniye bekletilmiş ve steril saf su ile birkaç defa durulanmıştır. Sonrasında 10 dakika süresince 1-2 damla Tween-20 içeren \% 15'lik sodyum hipoklorit $(\mathrm{NaClO})$ çözeltisinde tutulmuş ve tekrardan birkaç defa steril saf su ile durulanmışlardır. 
Tomurcuklardan anterlerin alınması için, steril kabinde steril edilmiş filtre kağıtları üzerinde, steril edilmiş pens ve bistüriler ile tomurcuklar açılarak, anterlere zarar verilmeden filamentlerinden ayrılarak petri kaplarındaki besin ortamlarına yerleştirilmişlerdir. Her bir tomurcuktan çıkarılan 5-6 adet anter, tek bir petri kabına yerleştirilmiştir. Enfeksiyonun önlenmesi için petri kaplarının etrafi streç film ile sarılmış ve sıcaklık ön uygulaması için inkübatöre yerleştirilmiştir (Taşkin ve ark., 2011).

Temel besin ortamı olarak MS (Murashige ve Skoog, 1962) kullanılmıştır. Anterler ilk aşamada; $30 \mathrm{~g} / \mathrm{L}$ sakkaroz $+2.5 \mathrm{~g} / \mathrm{L}$ aktif kömür $+15 \mathrm{mg} / \mathrm{L} \mathrm{AgNO}_{3}+4 \mathrm{mg} / \mathrm{L} \mathrm{NAA}+0.5 \mathrm{mg} / \mathrm{L}$ BAP + $6.5 \mathrm{~g} / \mathrm{L}$ agar içeren MS besin ortamında kültüre alınmışlardır (Shimira ve ark., 2019a). Sonrasında anterler, $30 \mathrm{~g} / \mathrm{L}$ sakkaroz ve $6.5 \mathrm{~g} / \mathrm{L}$ agar içeren ve büyümeyi düzenleyici içermeyen MS besin ortamına aktarılmışlardır (Shimira ve ark., 2019a). Elde edilen embriyolar da aynı besin ortamına alınmışlardır (ikinci besin ortamı) (Shimira ve ark., 2019a). Petri kaplarına yerleştirilen anterler önuygulama amacıyla, inkübatörde $+35^{\circ} \mathrm{C}$ 'de ve karanlık koşullarda 2 gün süresince ön uygulamaya tabi tutulmuşlardır (Taşkin ve ark., 2011). Ön uygulamayı takiben petriler, $25 \pm 1^{\circ} \mathrm{C}$ sıcaklık, 3600 lux gücündeki floresan ile aydınlatılan, 16 saat aydınlık-8 saat karanlık 1şık rejimine sahip kültür odasında bekletilmişlerdir (Taşkin ve ark., 2011).

Köklenen bitkilerin dış ortama adaptasyonlarını sağlamak amacıyla, tüplere sarılı streç film çıarılarak 1 gün, kültür tüplerinin kapakları gevşetilerek 1 gün ve kapaklar tamamen açılarak 1 gün bekletilmişlerdir. Sonrasında bitkiler tüplerden uzun pens yardımıyla köklere zarar vermeden dikkatlice çıkarılmış ve kökleri besin ortamı kalıntılarından tamamen temizlenene kadar musluk suyu altında yıkanmıştır. Bitkilerin kökleri fungusitli suya daldırılmış, bitkiler steril 2 hacim torf - 1 hacim perlit karışımı bulunan viyollere-saksılara dikilmiş ve ilk sulama fungusitli su ile yapılmıştır. Bitkiler birkaç hafta süresince \% 90-100 nem içeren alçak plastik tüneller içine yerleştirilmiş, bitkilerin bulunduğu ortam, yapraklara ve tünel içine sürekli su püskürtülmesi yoluyla nemli tutulmuştur. Tünellerin örtüleri kademeli olarak açılarak, dış ortama yavaş şekilde alışmaları sağlanmıştır (Şekil 1).

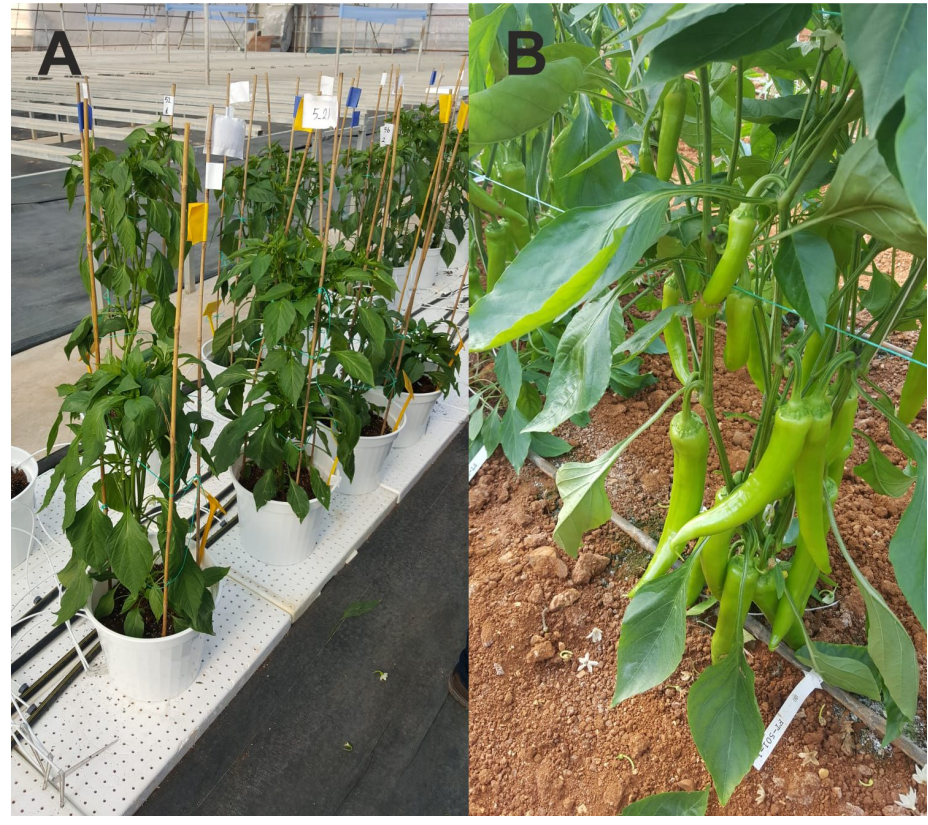

Şekil 1. Anter kültürü sonucu geliştirilerek dış koşullara alıştırılan biber bitkileri; dış koşullara alıştırma (A), diş koşullara adapte olup ürün aşamasındaki biber bitkileri (B).

Denemelerde; kültüre alınan anter sayısı, embriyo oluşturan anter sayısı, kallus oluşturan anter sayısı, embriyo sayısı, bitkiye dönüşen embriyo sayısı ve gelişen bitki sayıları kaydedilmiştir.

Embriyo oluşturan anter oranı; embriyo oluşturan anter sayısının, anter sayısına oranı ile hesaplanmıştır.

Kallus oluşturan anter oranı; kallus oluşturan anter sayısının, anter sayısına oranı ile hesaplanmıştır.

Embriyo oranı; embriyo sayısının, anter sayısına oranı ile hesaplanmıştır. 
Bitkiye dönüşen embriyo oranı; bitkiye dönüşen embriyo sayısının tüm oluşan embriyolara oranı ile hesaplanmıştır.

Deneme, tesadüf parselleri düzenine göre 4 tekerrürlü, her tekerrürde 5 petri olacak şekilde yapılmıştır. Hesapla bulunan yüzde değerlere açı transformasyonu uygulandıktan sonra, varyans analizi yapılmıştır. Elde edilen verilerin değerlendirilmesinde, SAS temeli üzerine kurulu JMP 8.1 istatistik paket programı kullanılmıştır. Elde edilen sonuçlar, \% 5 önem düzeyinde LSD testi ile karşılaştırılmıştır.

\section{Bulgular}

Çizelge 2'de, her bir genotip için anter sayısı, embriyo oluşturan anter sayısı ve kallus oluşturan anter sayısı 4 tekerrür için tekerrür ortalaması şeklinde verilmiştir. Embriyo oluşturan anter sayısı ortalamaları, 5 ile 42.5 arasında değişmiştir. Genotiplerde anter sayısı farklı olduğu için (Çizelge 2), genotipleri tekerrürlerin embriyo oluşturan anter sayılarının ortalamaları şeklinde karşılaştırmak, doğru sonuca yöneltmeyecektir. Bu nedenle, hem embriyo oluşturan hem de kallus oluşturan anter sayısı için, 100 anter başına embriyo ve kallus oluşturan anter sayıları hesaplanarak Çizelge 2'de sunulmuştur. Bu açıdan, 100 anter başına embriyo oluşturan anter sayısı ortalamaları, 9.16 ile 74.52 arasında değişmiş, en yüksek değer 74.52 embriyo oluşturan anter/100 anter ile FT-1173 no'lu genotipten elde edilmiştir. Bu genotipi, FT-500 (72.91 embriyo oluşturan anter/100 anter), FT-501 (71.87 embriyo oluşturan anter/100 anter), FT-509 (63.88 embriyo oluşturan anter/100 anter), FT-908 (48.96 embriyo oluşturan anter/100 anter) ve FT-508 (48.21 embriyo oluşturan anter/100 anter) no'lu genotipleri izlemiş, en düşük değer ise FT-1178 (9.16 embriyo oluşturan anter/100 anter) no'lu genotipten elde edilmiştir. Yüz anter başına ortalama kallus oluşturan anter sayısı açısından ise, sonuçlar 2.37 ile 45.83 arasında değişmiş, FT-902 (45.83 kallus oluşturan anter/100 anter) ve FT-903 (39.25 kallus oluşturan anter/100 anter) genotiplerinden en yüksek değerler elde edilmiştir. Bu genotipleri; FT-1175 (21.43 kallus oluşturan anter/100 anter), FT-1178 (20.83 kallus oluşturan anter/100 anter), FT-1181 (15.41 kallus oluşturan anter/100 anter), FT-1173 (14.85 kallus oluşturan anter/100 anter) ve FT-1180 (14.09 kallus oluşturan anter/100 anter) takip etmiş, en düşük performans ise FT-501 (2.37 kallus oluşturan anter/100 anter) no'lu genotipte gözlemlenmiştir.

Çizelge 2. Çalışmada kullanılan biber genotiplerinin kültüre alınan anter, embriyo ve kallus oluşturan anter sayıları

\begin{tabular}{|c|c|c|c|c|c|}
\hline Genotip & AS (adet) & EOAS (adet) & EOAS/100 A (\%) & KOAS (adet) & KOAS/100 A (\%) \\
\hline FT-263 & 92.5 & 20 & 22.62 fgh $(28.40)$ & 4 & 4.52 bcd (12.28) \\
\hline FT-500 & 25 & 18.75 & $72.91 \mathrm{a}(58.64)$ & 1.25 & 5.42 bcd (13.46) \\
\hline FT-501 & 31.25 & 20 & $71.87 \mathrm{a}(57.97)$ & 1.5 & $2.37 \mathrm{~d}(8.86)$ \\
\hline FT-507 & 47.5 & 15 & $30.06 \mathrm{~d}-\mathrm{g}(33.24)$ & 1.25 & 3.96 bcd (11.48) \\
\hline FT-508 & 85 & 42.5 & $48.21 \mathrm{bc}(43.97)$ & 4.75 & $6.96 \mathrm{bcd}(15.30)$ \\
\hline FT-509 & 45 & 28.75 & $63.88 \mathrm{ab}(53.06)$ & 1.25 & $6.38 \mathrm{bcd}(14.63)$ \\
\hline FT-900 & 32.5 & 11.25 & $34.61 \mathrm{c}-\mathrm{g}(36.04)$ & 2.5 & 8.37 bcd (16.82) \\
\hline FT-901 & 32.5 & 11.25 & 40.0 cde $(39.23)$ & 2.5 & 13.17 bcd (21.28) \\
\hline FT-902 & 22.5 & 7.5 & $43.75 \mathrm{~cd}(41.41)$ & 5 & $45.83 \mathrm{a}(42.61)$ \\
\hline FT-903 & 22.5 & 7.75 & 42.75 cde $(40.83)$ & 5 & 39.25 a (38.79) \\
\hline FT-905 & 52.5 & 22.5 & 40.21 cde $(39.35)$ & 3.75 & $9.25 \mathrm{bcd}(17.71)$ \\
\hline FT-906 & 90 & 19.75 & $20.68 \mathrm{gh}(27.05)$ & 3.25 & 4.94 bcd (12.84) \\
\hline FT-907 & 22.5 & 8.75 & 39.37 cde $(38.86)$ & 1.25 & $6.62 \mathrm{bcd}(14.91)$ \\
\hline FT-908 & 45 & 22.5 & 48.96 bc $(44.40)$ & 2.5 & $6.04 \mathrm{bcd}(14.23)$ \\
\hline FT-1173 & 25 & 18.75 & 74.52 a (59.68) & 3 & 14.85 bcd (22.67) \\
\hline FT-1174 & 40 & 11.75 & 27.50 d-g (31.63) & 2.5 & 11.87 bcd (20.15) \\
\hline FT-1175 & 22.5 & 5 & $19.64 \mathrm{gh}(26.31)$ & 2.5 & $21.43 \mathrm{~b}(27.58)$ \\
\hline FT-1178 & 45 & 5 & $9.16 \mathrm{~h}(17.62)$ & 7.5 & 20.83 bc $(27.16)$ \\
\hline FT-1179 & 32.5 & 10 & 30.62 d-g (33.60) & 3.75 & 13.12 bcd (21.24) \\
\hline FT-1180 & 37.5 & 8.75 & 21.59 fgh (27.69) & 6.25 & 14.09 bcd (22.05) \\
\hline FT-1181 & 65 & 25 & $37.29 \mathrm{c}-\mathrm{f}(37.64)$ & 9.25 & $15.41 \mathrm{bcd}(23.11)$ \\
\hline FT-1182 & 37.5 & 10 & 26.78 efg (31.16) & 2.75 & $7.41 \mathrm{bcd}(15.80)$ \\
\hline FT-1183 & 62.5 & 27.5 & $47.5 \mathrm{bc}(43.57)$ & 6.75 & 11.90 bcd (20.18) \\
\hline \multicolumn{6}{|c|}{$\operatorname{LSD}_{\mathrm{EOAS}} / 100 \mathrm{~A} * * *=16.57 \operatorname{LSD}_{\mathrm{KOAS}} / 100 \mathrm{~A} * *=17.43$} \\
\hline
\end{tabular}

(1): Aynı sütunda ayrı harflerle gösterilen ortalamalar arasındaki istatistiksel farklılıklar önemli bulunmuştur.

(2): Ö.D.: Önemli değil; *. $\mathrm{P}<0.05$. **p $\leq 0.01$. ***p $\leq 0.001$ 'i ifade etmektedir. 
Parantez içindeki değerler, açı transformasyonu yapılmış değerlerdir.

AS: Anter Sayısı, EOAS: Embriyo Oluşturan Anter Sayısı, EOAS/100 A: Embriyo Oluşturan Anter Sayısı/100 Anter, KOAS: Kallus Oluşturan Anter Sayısı, KOAS/100 A: Kallus Oluşturan Anter Sayısı/100 Anter.

Anter kültürü denemelerinde genotiplerin performanslarının karşılaştırılmasında, genellikle 100 anter başına hesaplanan embriyo sayısı göz önünde bulundurulmaktadır. Bu çalışmada da, bu hesaplamalar yapılarak Çizelge 3'de sunulmuştur. Yüz anter için ortalama embriyo sayıları, 0.83 ile 44.44 arasında değişmiştir (Şekil 2). En yüksek oran, 44.44 embriyo/100 anter ile FT-509 genotipinde gözlemlenmiş, bu genotip; FT-508 (23.61 embriyo/100 anter), FT-1181 (23.37 embriyo/100 anter), FT-905 (22.89 embriyo/100 anter), FT-501 (21.67 embriyo/100 anter) ve FT-1179 (20.37 embriyo/100 anter) genotipleri tarafindan takip edilmiştir. En düşük performansı, 0.83 adet embriyo/100 anter ile FT-1178 genotipi göstermiştir. Ortalama bitkiye dönüşen embriyo sayısı, 0.5 ile 20 arasında değişmiştir. Oluşan embriyoların tamamı bitkiye dönüşebilmiştir. Bu nedenle, 100 anter için ortalama bitki oluşturan embriyo sayısı değerleri, 100 anter için ortalama embriyo sayıları ile aynı olmuştur. Her genotipte bitki oluşturan embriyo sayısı ortalamaları açısından ise, en yüksek bitki sayısı ortalama 20 adet ile FT-508 no'lu genotipte gözlemlenmiş ve FT-509 (17.5 bitki-), FT-1181 (16 bitki), FT-905 (12 bitki), FT-263 (10.5 bitki) ile FT-507 (8.25 bitki) genotipleri tarafından takip edilmiştir. En düşük bitki sayısı ise 0.5 adet ile FT-1178 no'lu genotipte gözlemlenmiştir. Gelişen bitki sayısı ise, 0.5 ile 15.75 arasında değişmiştir. En yüksek performans; FT-508 (15.75 bitki), FT-1181 (14.75 bitki), FT509 (12.5 bitki), FT-263 (8.25 bitki) ve FT-908 (7.25 bitki) genotiplerinde kaydedilirken, en düşük performansı 0.5 ile FT-902 ve FT-1178 genotipleri göstermiştir.

Çizelge 3. Denemede farklı biber genotiplerden anter kültürü yoluyla elde edilen embriyo ve bitki say1lar1

\begin{tabular}{|c|c|c|c|c|}
\hline Genotip & ES (adet) & $\mathrm{ES} / 100 \mathrm{~A}(\%)$ & BDES (adet) & GBS (adet) \\
\hline FT-263 & 10.5 & 11.47 efg (19.77) & 10.5 & 8.25 \\
\hline FT-500 & 2.25 & $9.37 \mathrm{fg}(17.68)$ & 2.25 & 1.5 \\
\hline FT-501 & 6 & $21.67 \mathrm{bc}(27.61)$ & 6 & 5 \\
\hline FT-507 & 8.25 & $16.52 \mathrm{~b}-\mathrm{f}(23.89)$ & 8.25 & 6.75 \\
\hline FT-508 & 20 & $23.61 \mathrm{~b}(29.06)$ & 20 & 15.75 \\
\hline FT-509 & 17.5 & $44.44 \mathrm{a}(41.8)$ & 17.5 & 12.5 \\
\hline FT-900 & 3.5 & $9.87 \mathrm{fg}(18.08)$ & 3.5 & 3 \\
\hline FT-901 & 3.75 & $12.16 \mathrm{efg}(20.38)$ & 3.75 & 2 \\
\hline FT-902 & 1.5 & $4.58 \mathrm{~h}(8.80)$ & 1.5 & 0.5 \\
\hline FT-903 & 2.25 & $12.75 \mathrm{~d}-\mathrm{g}(20.49)$ & 2.25 & 1.75 \\
\hline FT-905 & 12 & $22.89 \mathrm{bc}(28.56)$ & 12 & 6.25 \\
\hline FT-906 & 6.75 & $7.12 \mathrm{~g}(15.29)$ & 6.75 & 4.75 \\
\hline FT-907 & 2.5 & $11.66 \mathrm{efg}(19.92)$ & 2.5 & 2.5 \\
\hline FT-908 & 7.75 & 17.50 b-e $(24.70)$ & 7.75 & 7.25 \\
\hline FT-1173 & 4 & $16.19 \mathrm{~b}-\mathrm{f}(23.52)$ & 4 & 2.75 \\
\hline FT-1174 & 7.25 & $18.87 \mathrm{~b}-\mathrm{e}(25.74)$ & 7.25 & 5.25 \\
\hline FT-1175 & 1.25 & $3.57 \mathrm{~h}(7.71)$ & 1.25 & 0.75 \\
\hline FT-1178 & 0.5 & $0.83 \mathrm{~h} \mathrm{(3.71)}$ & 0.5 & 0.5 \\
\hline FT-1179 & 6.5 & $20.37 \mathrm{bcd}(26.80)$ & 6.5 & 3.75 \\
\hline FT-1180 & 6.25 & $15.69 \mathrm{~b}-\mathrm{f}(23.14)$ & 6.25 & 4 \\
\hline FT-1181 & 16 & $23.37 \mathrm{bc}(28.69)$ & 16 & 14.75 \\
\hline FT-1182 & 5.5 & $14.82 \mathrm{c}-\mathrm{f}(22.43)$ & 5.5 & 4.25 \\
\hline FT-1183 & 7.25 & 11.88 efg (20.15) & 7.25 & 6 \\
\hline \multicolumn{5}{|c|}{$\mathrm{LSD}_{\mathrm{ES} / 100 \mathrm{~A}} * * *=7.07$} \\
\hline
\end{tabular}

(1): Aynı sütunda ayrı harflerle gösterilen ortalamalar arasındaki istatistiksel farklılıklar önemli bulunmuştur.

(2): Ö.D.: Önemli değil; *. $\mathrm{P}<0.05 . * * \mathrm{p} \leq 0.01$. $* * * \mathrm{p} \leq 0.001$ 'i ifade etmektedir.

Parantez içindeki değerler, açı transformasyonu yapılmış değerlerdir.

ES: Embriyo Sayısı, ES/100 A: Embriyo Sayıs1/100 Anter, BDES: Bitkiye Dönüşen Embriyo Sayısı, GBS: Gelişen Bitki Sayıs1. 


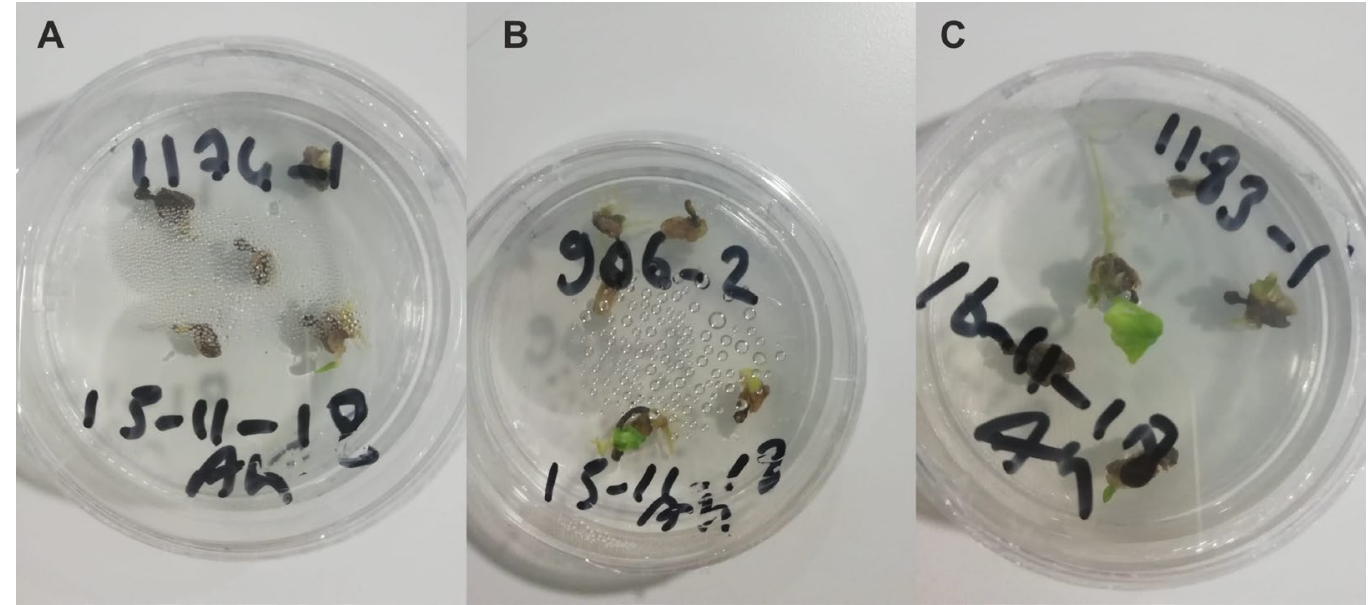

Şekil 2. Denemede kullanılan bazı biber genotiplerinin anter kültürüne tepkisi; FT-1174 (A), FT-906 (B), FT-1183 (C).

Koleva-Gudeva ve ark. (2007) tarafindan yapılan bir çalışmada; dokuz biber çeşidinin androgenesis tepkisi araştırılmıştır. Araştırıcılar çeşitleri anter kültürüne cevapları açısından kendi aralarında gruplamışlar; bu bağlamda Feferona, Vezena Luta, Sivrija ve Rotund çeşitleri cevap vermeyenler; Slatko Luta, Zlaten Medal ve Kurtovska Kapija çeşitleri zayıf cevap verenler; California Wonder çeşidi orta-iyi cevap veren ve Féherözön çeşidi çok iyi-mükemmel cevap veren olarak gruplandırılmıştır. Sunulan bu tez çalışmasında da, 100 anter sayısı başına embriyo açısından genotipleri karşlaştırarak, genotipleri kendi içinde değerlendirdiğimizde, Çizelge 4'deki gibi bir gruplama yapilabilir.

Çizelge 4. Denemede kullanılan biber genotiplerinin anter kültürü performansları açısından gruplandırılması (embriyo sayısı/100 anter için)

\begin{tabular}{|c|c|c|}
\hline Genotip No & Anter Kültürü Performansı & Biber Tipi \\
\hline FT-500 & Düşük (9.37) & Çarliston \\
\hline FT-900 & Düşük (9.87) & Kapya \\
\hline FT-902 & Düşük (4.58) & Kapya \\
\hline FT-906 & Düşük (7.12) & Kapya \\
\hline FT-1175 & Düşük (3.57) & Dolma \\
\hline FT-1178 & Düşük (0.83) & Dolma \\
\hline FT-263 & Orta (11.47) & Sivri \\
\hline FT-501 & Orta (21.67) & Çarliston \\
\hline FT-507 & Orta (16.52) & Çarliston \\
\hline FT-508 & Orta (23.61) & Çarliston \\
\hline FT-901 & Orta (12.16) & Kapya \\
\hline FT-903 & Orta (12.75) & Kapya \\
\hline FT-905 & Orta (22.89) & Kapya \\
\hline FT-907 & Orta (11.66) & Kapya \\
\hline FT-908 & Orta $(17.50)$ & Kapya \\
\hline FT-1173 & Orta (16.19) & Dolma \\
\hline FT-1174 & Orta (18.87) & Dolma \\
\hline FT-1179 & Orta (20.37) & Dolma \\
\hline FT-1180 & Orta (15.69) & Dolma \\
\hline FT-1181 & Orta (23.37) & Dolma \\
\hline FT-1182 & Orta (14.82) & Dolma \\
\hline FT-1183 & Orta (11.88) & Dolma \\
\hline FT-509 & Yüksek (44.44) & Çarliston \\
\hline
\end{tabular}

$\mathrm{Bu}$ gruplama genotiplerin kendi aralarında değerlendirmeleri ile kendimiz tarafından yapılmıştır: 0-10 embriyo/100 anter: Düşük, 10-30 embriyo/100 anter: Orta, 30-50 embriyo/100 anter: Yüksek. 


\section{Tartışma ve Sonuç}

Biberde anter kültürüne tepkide genotipin en önemli faktörlerden birisi olduğu, günümüze kadar yapılan birçok çalışma ile ortaya konulmuştur. Comlekcioglu ve ark. (2001) Kahramanmaraş ve Şanlıurfa'dan iki lokal biber popülasyonunun anter kültüründe $\mathrm{AgNO}_{3}(10 \mathrm{mg} / \mathrm{L})$ etkisini test etmişlerdir. Bu popülasyonların seçim nedeni, araştırıcıların daha önce yapmış oldukları çalışmalarda cevaplarının iyi olmaması olmuştur. Çalışmalarının sonunda, her iki popülasyonda da $\mathrm{AgNO}_{3}$ 'süz ortamlarda sonuç alamazken, $\mathrm{AgNO}_{3}$ 'lü ortamlardan sonuç almışlardır. Şanlıurfa popülasyonunda, 116 embriyo/100 tomurcuk ve 51.6 normal embriyo/100 tomurcuk sonuçları elde edilirken, Kahramanmaraş popülasyonunda sonuçlar, 35 embriyo/100 tomurcuk ve 35.7 normal embriyo/100 tomurcuk şeklinde olmuştur. Boyaci (2001) iki hibrid (Sirena F1ve Amazon F1) ve üç standart biber çeşidinin (Demre Sivrisi, Bağcı Çarliston ve Yalova Çarliston) anter kültüründe, farklı besin ortamlarının (2,4-D ve kinetinli MS, N, C\&R besin ortamları-aktif kömürlü ve aktif kömürsüz) etkisini araştırmıştır. Çalışma sonucunda; Demre Sivrisi, Bağcı Çarliston, Yalova Çarliston ve Amazon F1 çeşitlerinde, sadece kallus oluşumu gözlemlenmiştir. En yüksek kallus oluşumu, aktif kömür içermeyen $\mathrm{C} \& \mathrm{R}$ besin ortamında kaydedilmiştir. Kallustan bitki rejenerasyonu, sadece $\mathrm{N}$ besin ortamında gözlemlenmiştir ( $5 \mathrm{mg} / \mathrm{L}$ 2,4-D ve $5 \mathrm{mg} / \mathrm{L}$ kinetin). Embriyogenesise en iyi cevap, \% 4.4 oran ile N ortamında (5 mg/L 2,4-D, $5 \mathrm{mg} / \mathrm{L}$ kinetin ve \% 1 aktif kömür) gerçekleşmiştir. Sirena F1 ve Bağcı Çarliston çeşitlerinden embriyo ve sürgünler elde edilmiş, ancak bunların gelişimleri sağlanamamıştır. Ellialtioglu ve ark. (2001) tarafindan yapılan çalışmada, Kahramanmaraş biber popülasyonunda, aktif kömür ve havuç ekstraktı eklenmiş iki besin ortamı ve iki farklı inkübasyon koşulunun, anter kültürü üzerindeki etkisi denenmiştir. DDV (Dumas de Vaulx ve ark., 1981) kontrol ortamında, \% 0.45 cevap veren anter ve embriyo, DDV+aktif kömür ortamından $\% 1.05$ cevap veren anter ve embriyo, DDV+aktif kömür+havuç ekstraktı besin ortamından \% 0.83 cevap veren anter ve \% 1.17 embriyo; MS ortamında ise sadece kontrol besin ortamından $\% 0.66$ cevap veren anter ve $\% 0.82$ embriyo oranları ile sonuç alınabilmiştir. Her iki besin ortamının da tüm kombinasyonlarında, $35^{\circ} \mathrm{C}$ ' de 8 gün karanlıkta bekletme ve sonra $25^{\circ} \mathrm{C}$ sıcaklığa aktarma uygulamasından sonuç alınamamıştır. Yukarıda verilen sonuçların tamamı, $29^{\circ} \mathrm{C}$ 'de sürekli bekletme uygulamasından elde edilmiştir. Buyukalaca ve ark. (2004) tarafından yapılan bir çalışmada, $\mathrm{AgNO}_{3}$ 'ün farklı dozlarının $(5,10,15$ ve $20 \mathrm{mg} / \mathrm{L}$ ) ve donör bitki yetiştirme koşullarının (açık alan ve sera) anter kültürü üzerindeki etkisi, iki genotipin (Urfa: U-247 ve U-238) kullanımı ile araştırılmıştır. Çalışmada en başarılı sonuçlar, U-247 genotipinin seradan toplanan tomurcuklarının $15 \mathrm{mg} / \mathrm{L} \mathrm{AgNO}_{3}$ içeren besin ortamından elde edilmiştir. Genotiplerde, U-247 genotipinin tüm uygulamalardaki performans ortalamas1 17.5 embriyo/100 anter olurken, U-238 genotipinin performans1 4.9 embriyo/100 anter olarak kaydedilmiştir. Rodeva ve ark. (2004) tarafından biber anter kültüründe genotip etkisi araştırılmış ve bu amaçla hatlar, çeşitler ve hibridlerin performansı ayrı ayrı değerlendirilmiştir. Altı farklı hattın ortalamas1; \% 12.8 cevap veren anter, \% 1.38 embriyogenesisle cevap veren, \% 10.66 kallus oluşumu ile cevap veren, \% 0.04 toplam anter sayısina regenerantlar, \% 3.13 direk embriyo sayısına regenerantlar, altı çeşidin ortalaması; \% 12.69 cevap veren anter, \% 2.29 embriyogenesisle cevap veren, \% 10.36 kallus oluşumu ile cevap veren, \% 0.21 toplam anter sayısına regenerantlar, \% 9.99 direk embriyo sayısına regenerantlar; dört farklı hibridin ortalaması; \% 12.24 cevap veren anter, \% 1.39 embriyogenesisle cevap veren, \% 10.85 kallus oluşumu ile cevap veren şeklinde olmuştur. Ercan ve ark. (2006) donör bitki yetiştirme sezonunun ve bitki yaşının (kış için Kasım'dan Mayıs'a haftalık kültür, yaz için Nisan'dan Aralık'a haftalık kültür) biber anter kültürü üzerindeki etkisini, Kekova ve Sera Demre 8 biber çeşitlerinde araştırmışlardır. Kekova çeşidi; yaz sezonunda 4.97 embriyo/100 anter ve 2.26 bitki/100 anter, kış sezonunda ise 2.69 embriyo/100 anter ve 1.22 bitki/100 anter performansını göstermiştir. Sera Demre 8 çeşidinden ise yaz sezonunda 1.49 embriyo/100 anter ile 0.59 bitki/100 anter; kış sezonundan 4.26 embriyo/100 anter ve 1.36 bitki/100 anter sonuçları alınmıştır. Deneme sonuçları, farklı genotiplerin farklı zamanlarda daha iyi performans gösterdiğini doğrulamıştır. Çalışmada kullanılan çeşitlerin bir tanesi yaz döneminde, diğeri ise kış döneminde daha başarılı olmuştur. Çağlar ve ark (2004), Kahramanmaraş biberlerinde NAA (2.0, 4.0, $6.0 \mathrm{mg} / \mathrm{L}), 2$,4-D $(1.0,2.0,3.0,4.0 \mathrm{mg} / \mathrm{L})$, BAP $(0.1,1.0,2.0,3.0 \mathrm{mg} / \mathrm{L})$ ve kinetin $(0.1,1.0,5.0 \mathrm{mg} / \mathrm{L})$ 'in farkl1 dozlarını, aktif kömür (\% 0.25) ve $\mathrm{AgNO}_{3}(10 \mathrm{mg} / \mathrm{L})$ ilaveli ve farklı ön uygulamalı $\left(4^{\circ} \mathrm{C}\right.$ karanlıkta, $29^{\circ} \mathrm{C}$ karanlıkta, $35^{\circ} \mathrm{C}$ karanlıkta) 37 adet denemelerinin, $0.1 \mathrm{mg} / \mathrm{L} \mathrm{BAP}, 4 \mathrm{mg} / \mathrm{L}$ NAA, \% 0.25 aktif

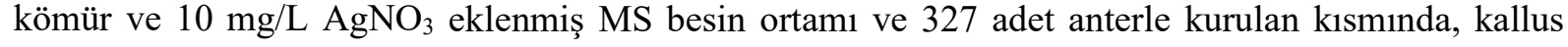


gelişimi olmaksızın, \% 2.8 oranında haploid embriyo gelişimi gözlemlemişlerdir. Çalışmada, 327 adet anterin üç adedinden dokuz adet embriyo gelişimi gözlemlenmiş, embriyo oluşturan anter oranı 0.92 olmuştur. Diğer denemelerde ise toplam 2903 anter kullanılmış, bu anterlerden 117 adet kallus oluşturan anter gözlemlenmiş, ancak bu anterlerden embriyo elde edilememiştir. Kallus oluşturan anter sayıs1 4.03 anter/100 anter olmuştur. Ercan ve Ayar Şensoy (2011) tarafindan biberin anter kültüründe genotip etkisinin araştırıldığ çalışmada; Atris çeşidinde 0.33 embriyo/100 anter, \% 39.10 kallus oluşturan anter sayıs1, 0.32 bitki/100 anter; Odesa çeşidinde 3.01 embriyo/100 anter, $\% 44.15$ kallus oluşturan anter, 0.67 bitki/100 anter; Demre çeşidinde 1.30 embriyo/100 anter, \% 19.48 kallus; DRH7118 çeşidinde 0.73 embriyo/100 anter, \% 21.10 kallus oluşturan anter; Yağllk biber'de 1.97 embriyo/100 anter, \% 39.76 kallus oluşturan anter, 0.39 bitki/100 anter; Yalova Çarliston'da \% 17.31 kallus oluşturan anter; Kandil'de \% 34.35 kallus oluşturan anter; Demre Sivrisi'nde 7.69 embriyo/100 anter, \% 19.41 kallus oluşturan anter, 2.20 bitki/100 anter; Sirena'da 0.35 embriyo/100 anter, \% 29.37 kallus oluşturan anter, 0.35 bitki/100 anter; Kekova'da 1.50 embriyo/100 anter, \% 33.83 kallus oluşturan, 0.43 bitki/100 anter; Sera-Demre 8'de 2.26 embriyo/100 anter, \% 28.51 kallus oluşturan anter, 1.13 bitki/100 anter elde edilmiştir. Alremi ve ark. (2014) tarafindan B, 151 ve 171 no'lu biber genotipleri ile Suriye'de kullanılan Alfajer çeşidi ve 16 farklı besin ortamı ile yapılan anter kültürü çalışmasında, Alfajer biber çeşidinde 1.32 embriyo/100 anter, 0.90 bitki/100 anter; B biber genotipinde 1.33 embriyo/100 anter, 1.26 bitki/100 anter; 171 no'lu biber genotipinde 0.24 embriyo/100 anter, 0.16 bitki/100 anter ve 151 no'lu biber genotipinde 0.57 embriyo/100 anter ile 0.42 bitki/100 anter gözlemlenmiştir. Olszewska ve ark. (2014) farklı biber çeşit ve genotipleri, bunların F1'leri, farklı hatlar, farklı biber türleri (C. baccatum, C. chinense, C. frutescens), farklı türlerin melezlenmesiyle oluşan F1'ler ve dihaploid hatlarda anter kültürü denemeleri yapmışlar ve değişken sonuçlar elde etmişlerdir. Bu denemeler esnasında, farklı kinetin dozları ve anterlerin farklı inkübasyon süreleri de test edilmiştir. Farklı türlerden sadece $C$. frutescens'de 16 gün inkübasyonda $0.1 \mathrm{mg} / \mathrm{L}$ kinetinde $\% 1.54,0.3 \mathrm{mg} / \mathrm{L}$ kinetinde ise $\% 0.77$ oranında başarı elde etmişlerdir. En yüksek sonuçlar, 16 gün inkübasyon $0.1 \mathrm{mg} / \mathrm{L}$ kinetinde $\mathrm{AC} 7$ dihaploid hattında $\% 6.15$ olarak ve takibinde 16 gün inkübasyonda $0.1 \mathrm{mg} / \mathrm{L}$ kinetinde $\mathrm{F} 1(\mathrm{ATZ} \times \mathrm{PO})$ bitkilerinde $\% 4.62$ olarak tespit edilmiştir. Ozsan \& Onus (2017), dört farklı biber çeşidinin anter kültüründe, vitamin B bileşiklerinin etkisini araştırmışlardır. Çalışmalarında denenen altı farklı besin ortamında, Belissa çeşidinde 3.73 embriyo/100 anter, 2.67 bitki/100 anter, 7.66 kallus oluşturan anter/100 anter; Benino çeşidinde 1.15 embriyo/100 anter, 0.39 bitki/100 anter, 0 kallus oluşturan anter/100 anter; Kanyon çeşidinde 0.19 embriyo/100 anter, 0.19 bitki/100 anter, 0.38 kallus oluşturan anter/100 anter ve Filinta çeşidinde 0.16 embriyo/100 anter, 0.17 bitki/100 anter, 0 kallus oluşturan anter/100 anter kaydetmişlerdir. Çalışma sonucunda, farklı vitamin B bileşiklerinin androgenesisi olumlu etkilediğini tespit etmişlerdir. Ozsan \& Onus (2018), dört farklı biber çeşidi ve 12 farklı besin ortamı kombinasyonu kullanarak, anter kültürü çalışması yapmışlardır. Temel besin ortamı olarak MS ve Gamborg B5'i kullanmışlar ve aynı zamanda glutamin etkisini de test etmişlerdir. Çalışma sonucunda, Erciyes ve Filinta çeşidinde embriyo elde edilememiş; Belissa çeşidinde 34.46 embriyo/100 anter, 0.58 bitki/100 anter ve Ergenekon çeşidinde 30.0 embriyo/100 anter ile 0.61 bitki/100 anter kaydedilmiştir. Gelişen anter yüzdesi ise Erciyes çeşidinde \% 57.10, Belissa çeşidinde 42.79, Filinta çeşidinde \% 70.74 ve Ergenekon çeşidinde \% 58.69 olmuştur. Glutaminin androgenesis üzerinde olumlu bir etkiye sahip olduğu da gözlemlenmiş̧tir. Ata ve ark. (2019) tarafindan üç biber genotipi, bir çeşidi ve iki farklı besin ortamında bir sene süresince her ay tekrarlanan anter kültürü çalışmasında, Inan3363 çeşidinden 22.14 embriyo/100 anter, 12.17 embriyo oluşturan anter/100 anter; genotip 277A'dan 10.01 embriyo/100 anter, 5.30 embriyo oluşturan anter/100 anter, genotip 195 'de 4.29 embriyo/100 anter, 2.13 embriyo oluşturan anter/100 anter ve genotip 421'de 1.40 embriyo/100 anter ile 1.19 embriyo oluşturan anter/100 anter elde etmişlerdir. Shimira ve ark. (2019b), Ruanda'dan temin edilen Pili-Pili (C. chinense) çeşidinin anter kültürü performansını, bir Türk genotipi (A111) ve çeşidi (Inan 3363) ile karşılaştırmalı olarak değerlendirmişlerdir (iki Türk materyali, C. annuum'a aittir). İki Türk genotipinden, Inan 3363 çeşidinde 19.4 embriyo/100 anter kaydedilirken, A111 genotipinden 4.46 embriyo/100 anter tespit edilmiştir. Ata ve ark. (2019)'nın çalışmasında da Inan 3363 çeşidinin anter kültürü performansı araştırılmış ve iki farklı besin ortamının ve 12 ay deneme tekrarının ortalaması 22.14 embriyo/100 anter olmuştur. Ancak bu çeşit bazı ay ve besin ortamlarında, \% 60'ın üzerinde de performans göstermiştir. Shimira ve ark. (2019b)'nın araştırmasında Inan 3363 çeşidinin seçilmesi nedeni, Ata ve ark. (2019)'nın denemelerinde yüksek performans göstermesi olmuştur. Shimira ve ark. 
(2019a) tarafından yapılan ve 2 farklı nematoda dayanıklı olarak tespit edilen biber genotipinin anter kültürüne tepkisinin belirlenmesinin hedeflendiği çalışmada; Alata 2095 genotipinde 45.51 embriyo/100 anter, 39.04 bitki/100 anter ve Alata 2096 genotipinde 2.25 embriyo/100 anter, 1.97 bitki/100 anter kaydedilmiştir. Tüm bu çalışmalarda açıkça görülebildiği gibi, biberde anter kültüründe genotip etkisi yüksektir. Bazı genotiplerin, aynı besin ortamında ve aynı koşullarda anter kültürüne tepkisi olumlu olurken, bazı genotiplerinki zayıf kalabilmektedir. Tepkisi zayıf olan genotipler, farklı dozlardaki büyümeyi düzenleyicilerle desteklenmiş besin ortamlarında veya farklı zamanlarda (sezonlarda) kültüre alındığında veya farklı ön uygulamalara maruz bırakıldığında (Ata ve ark., 2019) performansları yükselebilmektedir. Örneğin, sıcak koşullara adapte genotipler, Temmuz-Ağustos gibi sıcak aylarda (normalde Akdeniz iklim kuşağı ülkeleri için tavsiye edilmeyen dönemler) androgenesise yüksek tepki verebilmekte ya da soğuğa dayanıklı genotipler, normalde çoğu genotipten tepki alınmayan Aralık-Ocak gibi soğuk aylarda yüksek performas (Ata ve ark., 2019) gösterebilmektedir. Büyümeyi düzenleyicilerin tipi ve konsanstrasyonu da, kültür sezonuna veya genotipe göre değişebilmektedir (Ata, 2011). Sunulan bu çalışmada da genotiplerin anter kültürüne cevabı açısından, önemli farklılıklar görülmüştür (Çizelge 3). İstatistiksel analizler, sadece anter kültürüne tepkiyi karşılaştırmada en belirleyici hesaplama yöntemi olan, tekerrür ortalaması embriyo sayıs1/100 anter değerlerine uygulanmıştır. Bitki sayıları da, karşılaştırmada önemli bir faktördür. Bu çalışmada, embriyo sayısı ile bitki sayıları aynı olduğu için, istatistiksel analizler ayrıca bitki sayılarına uygulanmamıştır. FT-509 no'lu genotip, diğer genotiplere nazaran önemli derecede yüksek performas gösterirken, FT-1178 androgenesise en düşük cevabı vermiştir.

Koleva-Gudeva ve ark. (2007) tarafından yapılan bir çalışmada; dokuz biber çeşidinin androgenesis tepkisi araştırılmıştır. Feferona, Slatko Luta, Vezena Luta, Sivrija, Zlaten Medal, Kurtovska Kapija, California Wonder, Rotund ve Féherözön çeşitlerinden; Feferona, Vezena Luta, Sivrija ve Rotund çeşitleri anter kültürüne tepki vermemiş; Slatko Luta çeşidi \% 2.43 embriyogenik anter ve 3.33 embriyo/100 anter, Zlaten Medal çeşidi \% 3.31 embriyogenik anter ve 3.66 embriyo/100 anter, Kurtovska Kapija çeşidi \% 1.55 embriyogenik anter ve 2.66 embriyo/100 anter, California Wonder çeşidi \% 6.16 embriyogenik anter ve 5.66 embriyo/100 anter ve Féherözön çeşidi \% 33.66 embriyogenik anter ve 55.36 embriyo/100 anter oranlarında tepki vermişlerdir. Araştırıcılar çeşitleri anter kültürüne cevapları açısından kendi aralarında gruplamışlar; bu bağlamda Feferona, Vezena Luta, Sivrija ve Rotund çeşitleri cevap vermeyenler; Slatko Luta, Zlaten Medal ve Kurtovska Kapija çeşitleri zayıf cevap verenler; California Wonder çeşidi orta-iyi cevap veren ve Féherözön çeşidi çok iyi-mükemmel cevap veren olarak gruplandırılmıştır. Buna benzer şekilde sunulan bu çalışmada da; FT-509 no'lu genotipin anter kültürü performans1 44.44 embriyo/100 anter ile yüksek; FT-508, FT1181, FT-905, FT-501, FT-1179, FT-1174, FT-908, FT-507, FT-1173, FT-1180, FT-1182, FT-903, FT-901, FT-1183 FT-907 ve FT-263 genotiplerinin anter kültürü performans1 11.47-23.61 embriyo/100 anter ile orta; FT-900, FT-500, FT-906, FT-902, FT-1175 ve FT-1178 genotiplerinin performans1 0.83-9.87 embriyo/100 anter ile düşük olarak belirlenmiştir (Çizelge 4).

Niklas-Novak ve ark. (2012) ('ATZ1' × 'TG') F2 hibridinin 20 adet bitkisinin, bireysel olarak anter kültürü performanslarını değerlendirmişlerdir. Çalışmadan elde edilen sonuçlar, 0.5 ile 16.5 embriyo/100 anter arasında değişmiş, ortalama 3.53 embriyo/100 anter olmuştur. Bu çalışma, anter kültürüne cevabın genotipin yanı sıra, aynı genotip içerisindeki bitkilerde bile değişken olduğunu göstermektedir.

Sonuçlar özetlenecek olursa, FT-509 no'lu genotip, 44.44 embriyo/100 anter ile en yüksek performansı göstermiştir. FT-509 no'lu genotipe anter kültürüne cevap açısından en yakın olan FT508 'in 23.61 embriyo/100 anter olan tepkisi ile kıyaslanacak olursa, denenen 23 genotip içerinde FT509 no'lu genotipin kendisine en yakın olan genotipin bile neredeyse iki katı değerinde performans gösterdiği açıkça görülmektedir. FT-1178 genotipi, 0.83 embriyo/100 anter ile androgenesise en düşük tepkiyi vermiştir. Bu genotipin gerçekten anter kültürüne tepki açısından inatçı olup olmadığını görebilmek için, farklı besin ortamları ve farklı büyümeyi düzenleyici konsantrasyonları ile denemeler yapilabilir. FT-1175 (3.57 embriyo/100 anter), FT-902 (4.58 embriyo/100 anter), FT-906 (7.12 embriyo/100 anter), FT-500 (9.37 embriyo/100 anter) ve FT-900 (9.87 embriyo/100 anter) genotipleri de, diğer genotiplere göre düşük performas göstermişlerdir. Ancak FT-1178 ile karşılaştırıldığında, bu genotiplerin en düşük değerini veren FT-1175 bile, FT-1178'in üç katından fazla embriyo üretmiştir. $\mathrm{Bu}$ çalışmada kullanılan genotiplerin androgenesis etkinliklerinin belirlenmesi ve bu genotiplerden dihaploid bitkilerin elde edilmesi ile özel firma tarafindan yürütülen ıslah çalışmaları hızlandırılmıştır. 
Biberde, anter kültürüne genotiplerin tepkisi değişken olmaktadır. Bu değişkenlikte genotiplerin genetik yapıları, donör bitki yetiştirilme koşulları, yetiştiricilik sezonu, besin ortamı ve besin ortamına ilave edilen büyümeyi düzenleyicilerin tipi ve konsantrasyonu gibi faktörler etkili olmaktadır. Bazı genotiplerin, bazı besin ortamı ve yetiştiricilik sezonlarında androgenesise cevabı düşük olurken, farklı besin ortamı ve dönemlerde performas yükselebilmektedir. Bu nedenle, sunulan bu çalışmada anter kültürüne cevabı düşük olarak tespit edilen genotiplerin, farklı besin ortamlarında da denenmesi önerilebilir. Benzer şekilde sezon etkisinin olup olmadığının anlaşılabilmesi için, genotiplerin yüksek sıcaklığa/düşük sıcaklığa tolerans/hassaslık durumları kontrol edilerek, daha uygun kültüre alma zamanları kontrol edilebilir.

\section{Teșekkür}

Çalışmanın yürütüldüğg̈ ARGEERA Bilimsel Araştırma Geliştirme Üretim Danışmanlık San. ve Tic. Ltd. Şti. (Antalya)'ne ve bitkisel materyallerini kullandığımız Semillas Fitó (İspanya)'ya destekleri için teşekkür ederiz. Değerli fikirlerinden faydalandığımız ve 07 Ocak 2019 tarihinde aramızdan ayrılan ancak kalbimizde yaşayan çok kıymetli hocamız Prof. Dr. Saadet BÜYÜKALACA'ya da sonsuz teşekkürlerimizi ve minnetimizi sunarız.

\section{Kaynakça}

Alremi, F., Taşkın, H., Sönmez, K., Büyükalaca, S., \& Ellialtığlu, Ş. (2014). Biber (Capsicum annuum L.)'de genotip ve besin ortamının anter kültürüne etkileri. Türk Tarım ve Doğa Bilimleri Dergisi, 1(2), 108-116.

Ata, A. (2011). Biberlerde (Capsicum annuum) anter kültüründe mevsim etkisi ve mikrospor gelişimi. (Yüksek Lisans Tezi), Çukurova Üniversitesi, Fen Bilimleri Enstitüsü, Adana, Türkiye.

Ata, A., Keleş, D., Taşkın, H., \& Büyükalaca, S. (2019). Effects of season, genotype, and nutrient medium on pepper anther culture and microspore development. Turk. J. Agric. For., 43, 123137.

Boyac1, H. F. (2001). The effects of different culture media added activated charcoal on production of haploid plant via anther culture of pepper (Capsicum annuum L.). (K. Abak., S. Büyükalaca, Y. Daşgan, editors). Paper presented at the Proc. of the $\mathrm{XI}^{\text {th }}$ EUCARPIA Meeeting on Genetics and Breeding of Capsicum \& Eggplant, 9-13 April 2001, Antalya, Turkey, pp. 137141.

Buyukalaca, S., Comlekcioglu, N., Abak, K., Ekbic, E., \& Kılıc, N. (2004). Effect of silver nitrate and donor plant growing conditions on production of pepper (Capsicum annuum L.) haploid embryos via anther culture. Eur. J. Hortic. Sci., 69(5), 206-209.

Çömlekçioğlu, N., \& Ellialtıŏlu, Ş. Ş. (2018). Review on the Research carried out on in vitro Androgenesis of Peppers (Capsicum annuum L.) in Turkey. Res. J. Biotechnol., 13(6), 75-84.

Comlekcioglu, N., Buyukalaca, S., \& Abak K. (2001). Effect of silver nitrate on haploid embryo induction by anther culture in pepper (Capsicum annuum L.). (K. Abak., S. Büyükalaca, Y. Daşgan, editors). Paper presented at the Proc. of the XIth EUCARPIA Meeeting on Genetics and Breeding of Capsicum \& Eggplant, 9-13 April 2001, Antalya, Turkey, pp. 133-136.

Çağlar, Ç., Aras, V., \& Bayram, A. (2004). Kurutmalık kırmızı biberlerde androgenesis yoluyla in vitro haploid embriyo uyartım1. Akdeniz Üniversitesi Ziraat Fakültesi Dergisi, 17(1), 87-94.

Dumas de Vaulx, R., Chambonnet, D., \& Pochard, E. (1981). In vitro anther culture in red pepper (Capsicum annuиm L.): improvement of the rate of plant production in different genotypes by treatments at $35^{\circ} \mathrm{C}$. Agronomie, 1, 859-864.

Ellialtioglu, S., Kaplan F., \& Abak, K. (2001). The effect of carrot extract and activated charcoal on the androgenesis of pepper. (K. Abak., S. Büyükalaca, Y. Daşgan, editors). Paper presented at the Proc. of the XIth EUCARPIA Meeeting on Genetics and Breeding of Capsicum \& Eggplant, 9-13 April 2001, Antalya, Turkey, pp. 142-145.

Ercan, N., \& Ayar Şensoy, F. (2011). Androgenic responses of different (Capsicum annuиm L.) cultivars. Biyoloji Bilimleri Araştırma Dergisi, 4(2), 59-61. 
Ercan, N., Ayar Sensoy, F., \& Sensoy, A. S. (2006). Influence of growing season and donor plant age on anther culture response of some pepper cultivars (Capsicum annuum L.). Sci. Hortic., $110(1), 16-20$.

Eroğlu, İ., Çamoğlu, G., \& Demirel, K. (2020). Termografi Tekniği ile Biber Bitkisinde Su Stresinin ve Bazı Fizyolojik Özelliklerin Belirlenmesi. Yüzüncü Yıl Üniversitesi Tarım Bilimleri Dergisi, 30(3), 486-497.

FAO. (2018). Food and Agriculture Organization of the United Nations, FAOSTAT. http://www.fao.org/faostat/en/\#data/QC Erişim Tarihi: 14.12.2019.

Keleş, D., Pınar, H., Ata, A., Taşkın, H., Yıldız, S., \& Büyükalaca, S. (2015). Effect of pepper types on obtaining spontaneous doubled haploid plants via anther culture. Hort Science, 50(11), 1671-1676.

Koleva-Gudeva, L. R., Spasenoski, M., \& Trajkova, F. (2007). Somatic embryogenesis in pepper anther culture: The effect of incubation treatments and different media. Sci. Hortic., 111, 114119.

Murashige, T., \& Skoog, F. 1962. A revised medium for rapid growth and bioassy with tobacco tissue cultures. Physiol. Plant, 15, 473-497.

Niklas-Nowak, A., Olszewska, D., Kisiala, A., \& Nowaczyk, P. (2012). Study of individual plant responsiveness in anther cultures of selected pepper (Capsicum spp.) genotypes. Folia Horticulturae, 24(2), 141-146.

Olszewska, D., Kisiala, A., Niklas-Nowak, A., \& Nowaczyk, P. (2014). Study of in vitro anther culture in selected genotypes of genus Capsicum. Turk. J. Biol., 38, 118-124.

Ozsan, T., \& Onus, N. (2017). In vitro Pepper (Capsicum annuum L.) Anther Culture: Can be Affected Via Vitamins B?. Biotechnology Journal International, 20(1), 1-13.

Ozsan, T., \& Onus, A.N. (2018). Does Glutamine Promote the Development of Pepper (Capsicum annuum L.) Anthers in vitro? Journal of Scientific and Engineering Research, 5(11), 228-236.

Öntürk, G., \& Çürük, S. (2019). Hatay'ın Farklı İlçelerinde Yetiştirilen Biber Köy Popülasyonlarında Bitki ve Meyve Özellikleri. Yüzüncü Yıl Üniversitesi Tarım Bilimleri Dergisi, 29(4), 689-701.

Rodeva, V. N., Irikova, T. P., \& Todorova, V. J. (2004). Anther culture of pepper (Capsicum annuиm L.): Comparative study on effect of the genotype. Biotechnol. Biotec. Eq., 18(3), 34-38.

Shimira, F., Yıldız, S., Baktemur, G., Keleş, D., Aydın, M. Z., Büyükalaca, S., \& Taşkın, H. (2019a). Investigation of Androgenesesis Capacity of Rwandan Pili-Pili Variety (Capsicum chinense L.) in Turkey. Yüzüncü Yıl Üniversitesi Fen Bilimleri Enstitüsü Dergisi, 24(3), 170-175.

Shimira, F., Keleş, D., Taşkın, H., \& Abak, K. (2019b). The Assessment of Androgenic Response of Two Nematode Resistant Pepper (Capsicum annuum L.) Genotypes. Turkish Journal of Agriculture - Food Science and Technology, 7(12), 2103-2110.

Taşkin, H., Büyükalaca, S., Keleş, D., \& Ekbiç, E. (2011). Induction of microspore-derived embryos by anther culture in selected pepper genotypes. Afr. J. Biotechnol., 10(75), 17116-17121.

TÜİK. (2018). Türkiye İstatistik Kurumu. http://www.tuik.gov.tr. Erişim Tarihi: 14.12.2019 